\title{
Modulation of Cyclic Nucleotides in Isolated Rat
}

\section{Glomeruli}

\author{
ROLE OF HISTAMINE, CARBAMYLCHOLINE, PARATHYROID \\ HORMONE, AND ANGIOTENSIN-II
}

\author{
Vicente E. Torres, Thomas E. Northrup, Richard M. Edwards, \\ Sudhir V. SHAH, and ThOmas P. Dousa, Nephrology Research Laboratories, \\ Department of Internal Medicine, Division of Nephrology, and \\ Department of Physiology and Biophysics, Mayo Clinic i Foundation, \\ Rochester, Minnesota 55901
}

\begin{abstract}
A B S T R A C T Because glomerular functions are modulated by numerous humoral agents, probably acting through cyclic nucleotides, the effects of some polypeptide hormones and biogenic amines on cyclic AMP (cAMP) and cyclic 3',5'-guanosine monophosphate (cGMP) were studied in glomeruli isolated from rat renal cortex. Glomeruli and cortical tubules were prepared by a combination of sieving and density-gradient centrifugation. Under basal conditions, the contents of cAMP and cGMP in glomeruli were significantly higher than in tubules and unfractionated renal cortical tissue.

Histamine caused a striking increase in cAMP in glomeruli $(+\Delta \% 675 \pm 87)$ and, to a lesser degree, increased cAMP in tubules $(+\Delta \% 103 \pm 25)$ or in tissue slices. This stimulation was dose-dependent in the range of $1 \mu \mathrm{M}-1 \mathrm{mM}$ histamine. Metiamide (an $\mathrm{H}_{2^{-}}$ antagonist), but not pyrilamine (an $\mathrm{H}_{1}$-antagonist) blocked the effect of histamine on cAMP, which indicates that histamine causes its effect via interaction with $\mathrm{H}_{2}$ receptors. Histamine caused less extensive increases in cGMP in both glomeruli and tubules. Carbamylcholine caused a marked increase in cGMP in glomeruli $(+\Delta 295 \pm 7)$ and a much lower increase in tubules $(+\Delta \% 70 \pm 20)$; these effects were blocked by
\end{abstract}

Preliminary reports of this work were published as abstracts: 1978. Clin. Res. 26: 43A, 477A, and 545A.

Dr. T. P. Dousa is an Established Investigator of the American Heart Association (AHA-74182). Dr. S. V. Shah is the recipient of the fellowship training grant (AM-07013) from the U. S. Public Health Service. Address reprint requests to Dr. Dousa.

Received for publication 6 February 1978 and in revised form 31 July 1978. atropine. Parathyroid hormone $(1 \mu \mathrm{g} / \mathrm{ml})$ increased cAMP and, to a much lesser degree, also cGMP in glomeruli. In tubules, parathyroid hormone caused much more extensive increases in cAMP than in glomeruli; no changes, or rather a small decline in cGMP, was observed. Angiotensin-II $(2 \mu \mathrm{M})$ markedly lowered cAMP in glomeruli $(-\Delta \%-45 \pm 8)$ and in tubules $(-\Delta \%$ $33 \pm 7)$ but had no effect on cGMP. Bradykinin $(20 \mu \mathrm{M})$ did not consistently influence either cAMP or cGMP in glomeruli or tubules.

Present results demonstrate that cAMP and CGMP metabolism in glomeruli are controlled independently by humoral agents known to alter glomerular functions in vivo. Our findings are consistent with the view that histamine and cholinergic agents generated and (or) released locally in glomeruli or in their vicinity may play important roles as mediators of immunopathological injury of glomeruli, and that these effects are mediated by cAMP and (or) cGMP through interaction with $\mathrm{H}_{2}$ receptors and muscarinic receptors. Likewise, our results suggest that the effects of angiotensin-II and parathyroid hormone on glomerular dynamics may be mediated by cyclic nucleotides.

Thus, we surmise that extrarenal as well as intrarenal humoral agents may play an important role in the pathology and physiology of glomeruli through mediation of either cAMP, cGMP, or both.

\section{INTRODUCTION}

It has become increasingly evident in recent years that many extrarenal and intrarenal humoral agents may modulate diverse aspects of glomerular function (1). For example, the administration of agents such as para- 
thyroid hormone $(\mathrm{PTH})^{1}(2)$, angiotensin $(3,4)$, bradykinin, acetylcholine $(5,6)$, and others (1) causes changes in glomerular microcirculation, hydraulic permeability, or in the ultrafiltration properties of glomerular membrane. Perhaps more importantly, some humoral factors, which are released in the course of inflammation, namely in the response to immunologic injury $(7,8)$ (such as histamine, acetylcholine, bradykinin) may, as in other tissues, play a crucial role in the pathogenesis of glomerular lesions such as glomerulonephritis, acute renal failure or renal allograft rejection. It has been extensively documented in extrarenal tissues that the actions of many of the above mentioned agents, especially local mediators of the immune response (8-10), are mediated at the cellular level by cyclic $3^{\prime}, 5^{\prime}$-adenosine monophosphate (cAMP) and cyclic 3',5'-guanosine monophosphate (cGMP).

Because glomeruli constitute only a small portion of renal cortex, it seems unlikely that studies on cyclic nucleotide dynamics in whole renal cortical tissue preparations could accurately reflect changes in glomeruli. Several recent findings suggest that cAMP and cGMP systems are indeed present in glomeruli and that they differ in some aspects from the rest of the renal cortical tissue. Adenylate cyclase (11-13) and guanylate cyclase (14) activities were detected in isolated glomeruli; guanylate cyclase was much more active in glomeruli than in tubules (14). It was also reported that some humoral agents, namely PTH, can influence adenylate cyclase in glomeruli (11-13). Cyclic nucleotide phosphodiesterases in glomeruli preferentially hydrolyze cGMP rather than cAMP (15), and are regulated differently than analogous tubular enzymes (16). Immunohistochemical analysis indicated the presence of cAMP or cGMP in glomeruli and their increase in response to $\mathrm{PTH}$ (17).

In view of the possibility that humoral agents, which may play a potentially important role in glomerular pathology and physiology, may act on glomeruli through mediation of cAMP or cGMP, we investigated the effects of some of the extrarenal or local polypeptide agents (PTH, angiotensin-II, bradykinin) and biogenic amines (histamine, cholinergic agents) on the cAMP and cGMP accumulation in the glomeruli isolated from the rat kidney cortex; the effects of these agents on cAMP and cGMP in isolated glomeruli were compared with the effects on tubules or tissue slices prepared from the same kidneys. Our results revealed that glomeruli not only have a higher capacity for accumulation of cAMP and cGMP than tubules and renal

\footnotetext{
${ }^{1}$ Abbreviations used in this paper: cAMP, adenosine3',5'-cyclic monophosphate; cGMP, guanosine- $3^{\prime}, 5^{\prime}$-cyclic monophosphate; KRB, Krebs-Ringer phosphate buffer; MIX, 1-methyl-3-isobutyl xanthine; PTH, parathyroid hormone; RIA, radioimmunoassay.
}

cortical slices but also that many agents (histamine, carbamylcholine, and PTH) dramatically influence cAMP and(or) cGMP levels in isolated glomeruli in a way different from that in tubules.

\section{METHODS}

Isolation of glomeruli. Tissues were obtained from adult male Sprague-Dawley rats which weighed 180-280 g, maintained on ad libitum standard diet Purina Laboratory Rat Chow (Ralston Purina Co., St. Louis, Mo.) and drinking tap water. After induction of pentobarbital anesthesia (50 $\mathrm{mg} / \mathrm{kg}$ ), a polyethylene catheter (PE-100) was inserted into the low abdominal aorta immediately above the bifurcation. Subsequently, the aorta was clamped above the renal arteries, the renal veins cut, and the kidneys perfused with $60-80 \mathrm{ml}$ of modified Krebs-Ringer phosphate buffer (KRB) of the following composition: $140 \mathrm{mM} \mathrm{NaCl}, 5 \mathrm{mM} \mathrm{KCl}, 1.2 \mathrm{mM} \mathrm{MgSO}_{4}$, $2.0 \mathrm{mM} \mathrm{CaCl}_{2}, 10 \mathrm{mM}$ glucose, $10 \mathrm{mM}$ sodium acetate, $2 \mathrm{mM}$ sodium phosphate, and $20 \mathrm{mM}$ Tris ( $\mathrm{pH} \mathrm{7.4).} \mathrm{The} \mathrm{interval}$ between clamping the aorta and the onset of the perfusion did not exceed $20 \mathrm{~s}$. After kidney surfaces were completely blanched, kidneys were removed and placed on an ice-cooled dissecting table. Cortical tissues from kidneys of two to three rats were pooled for one experiment. The cortex was dissected from the kidney and used for preparation of glomeruli and tubules. All subsequent preparative steps were performed at $4^{\circ} \mathrm{C}$. In some experiments, a part of the cortex was used to prepare cortical tissue slices $(0.5-\mathrm{mm}$ thickness) with a Stadie-Riggs tissue slicer (18); these cortical slices were washed several times in KRB. Glomeruli and tubules were prepared with a combination of sieving and density-gradient centrifugation; some major steps were adapted from the method of Nørgaard (19). The cortical tissue was minced, strained through a stainless steel sieve (220- $\mu \mathrm{m}$ opening), and subsequently passed through a hypodermic needle (gauge 23, Sherwood Medical Industries, Inc., St. Louis, Mo.). The resulting suspension of cortical tissue was washed four times in KRB by repeated centrifugation at $200 \mathrm{~g}$ for $1.5 \mathrm{~min}$ to eliminate debris and small tissue fragments. The resulting pellet was resuspended in $3 \mathrm{ml}$ of $26 \%$ Ficoll and was placed on the bottom of the centrifugation tube; 2 -ml layers of Ficoll solutions of decreasing concentration $(23,20$, and $11 \%)$ were layered over the pellet suspension (19). After centrifugation in a swinging bucket rotor JS-20 (Beckman refrigerated centrifuge, model J-21, Beckman Instruments, Inc., Spinco Div., Palo Alto, Calif.) for $10 \mathrm{~min}$ at $1,200 \mathrm{~g}$, glomeruli were collected from the interphase $11-20 \%$ and, if purity criteria met, also from the interphase $20-23 \%$. The pellet at the bottom of the tube contained large aggregates of tubular fragments. The pellet was suspended in cold KRB and passed through nylon screen (400$\mu \mathrm{m}$ opening, Nytex Co., Niles, Ill.) on which tubular fragments were retained. Tubular fragments were rinsed on the screen with $60-80 \mathrm{ml}$ of $\mathrm{KRB}$ to reduce glomerular contamination to a negligible level. Suspensions of glomerular and tubular fractions were again washed three or four times in ice-cold $\mathrm{KRB}$ by repeated centrifugation at $140 \mathrm{~g}, 1.5 \mathrm{~min}$ and resuspended in KRB.

The purity of each glomerular suspension was evaluated by light-microscopic examination and by counting of glomeruli. An aliquot of glomerular suspension $(50-100 \mu \mathrm{l})$ was mixed on the microscopic slide (10:1, vol/vol) with $0.1 \%$ toluidine blue solution in isotonic saline to visualize cellular elements and was examined under higher magnification $(\times 430)$ to evaluate first the structure of isolated glomeruli and then at the lower magnification $(\times 100)$ to determine the glomerular count of suspension. Isolated glomeruli were without capsules 
and the structure was well preserved. The purity of glomeruli was determined by counting at least 200 particles stained with toluidine blue, and only preparations which contained more than $95 \%$ of glomeruli were used for subsequent experiments. Tubular suspension was checked for absence of glomeruli. Glomeruli were also examined microscopically after fixation in $10 \%$ formol and staining with hematoxylineosin. This examination confirmed the intact structure of glomerular preparations. In some preparations, the alkalinephosphatase activity in homogenized glomeruli and tubules was also determined. The washed glomeruli and tubules were homogenized in a medium of the following composition: $0.25 \mathrm{M}$ sucrose, $5 \mathrm{mM}$ Tris, $3 \mathrm{mM} \mathrm{MgCl}_{2}, 1 \mathrm{mM}$ EDTA (pH 7.4) $(20: 1$ wet wt/vol) in a Teflon (E. I. DuPont deNemours \& Co., Wilmington, Del.) pestle-glass homogenizer with five strokes at $0-4^{\circ} \mathrm{C}$, and assayed for activity of alkaline phosphatase. Specific activity of alkaline phosphatase was significantly higher in tubular preparations (tubules: 8.12 \pm 0.4 ; glomeruli: $2.69 \pm 0.5 \mathrm{mM} / \mathrm{mg}$ protein $/ \mathrm{h} ; n=10 ; t$ test, $P<0.001$ ), a finding similar to another report from preparation of rat glomeruli and tubules (20).

Incubations. Freshly prepared glomeruli (2-5 mg wet wt) and tubules $(4-10 \mathrm{mg}$ wet $\mathrm{wt}$ ) were resuspended in $100 \mu \mathrm{l}$ of ice-cold KRB. In some experiments, cortical tissue slices (10-20 mg wet wt) were also suspended in $100-\mu \mathrm{l}$ aliquots of cold KRB. The tissue suspensions were distributed into $10-\mathrm{ml}$ glass homogenizer tubes (size A, Arthur H. Thomas Co., Philadelphia, Pa.) kept in crushed ice at $0^{\circ} \mathrm{C}$, and $250 \mu \mathrm{l}$ of $\mathrm{KRB}$ were added to these tubes to make the volume up to $350 \mu \mathrm{l}$. These suspensions were first preincubated at $37^{\circ} \mathrm{C}$ for $20 \mathrm{~min}$ in a Dubnoff shaking water bath (120 cycles/min). At the end of the 20 min preincubation period, $50 \mu \mathrm{l}$ of 5 mM 1-methyl-3-isobutyl xanthine (MIX) dissolved in KRB and either $100 \mu \mathrm{l}$ of KRB (controls), or hormones and drugs dissolved in $100 \mu \mathrm{l} \mathrm{KRB}$ were added to the various suspensions. These additions were made within a time interval of $6 \mathrm{~s}$. The final volume of each suspension then was $500 \mu \mathrm{l}$ of KRB (with $0.5 \mathrm{mM}$ MIX) and the final concentration of various test agents as indicated in Results. Stock solutions of hormones or drugs were kept at either $-20^{\circ} \mathrm{C}$ or $0^{\circ} \mathrm{C}$ as appropriate. Dilutions and $\mathrm{pH}$ adjustments were made immediately before incubation. After the addition of the various test agents and MIX, the tubes were incubated for an additional $2 \mathrm{~min}$ at $37^{\circ} \mathrm{C}$ in a metabolic, shaking water-bath. The incubation was terminated by the addition of $500 \mu \mathrm{l}$ of ice-cold $10 \%$ trichloroacetic acid (TCA) and immediate homogenization with a Teflon pestle (10 strokes).

A small aliquot $(30 \mu \mathrm{l})$ was taken from the TCA homogenate for the determination of protein; average total protein content per incubation mixture was $211 \pm 25 \mu \mathrm{g} /$ tube $( \pm \mathrm{SEM}$; $n=29$ ) for glomeruli, and $380 \pm 37 \mu \mathrm{g} /$ tube ( \pm SEM; $n=29$ ) for tubules. The remainder of the TCA homogenate was divided into two aliquots for determination of cAMP and cGMP by radioimmunoassay (RIA). Tracer amounts of $\left[{ }^{3} \mathrm{H}\right] \mathrm{cAMP}(6,500$ cpm, $0.25 \mathrm{pmol} / 10 \mu \mathrm{l})$ or $\left[{ }^{3} \mathrm{H}\right] \mathrm{cGMP}(6,500 \mathrm{cpm}, 0.25 \mathrm{pmol} / 10$ $\mu \mathrm{l})$ were added to the respective aliquots for monitoring recovery. Precipitated proteins were removed by centrifugation. The supernate was acidified with $200 \mu \mathrm{l}$ of $\mathrm{HCl}$ (final concentration $0.14 \mathrm{M}$ ) and the TCA was removed from the supernate by repeated extraction ( 3 times) with ethyl ether; remnants of ether were evaporated by heating, and samples were adjusted to neutral $\mathrm{pH}$ with $0.5 \mathrm{~N} \mathrm{NaOH}$. Aliquots of extracts were used for determinations of cyclic nucleotides by RIA, and for measurements of recovery. In preliminary experiments cAMP and cGMP were separated before RIA on formate-DOWEX-1 columns (Dow Chemical Co., Midland, Mich.) according to the method of Murad et al. (21). As observed also in other tissue systems $(22,23)$ analogous results were obtained with or without DOWEX-1 column separation, even if the extracts of the same tissue sample were simultaneously measured. Therefore, because of the small quantity of material, extracts were not routinely passed through DOWEX-1 columns before cAMP-RIA and cGMP-RIA.

Assays. Cyclic nucleotides were determined by RIA originally developed by Steiner et al. (24) and modified, to increase the sensitivity, by Harper and Brooker (25) and by Frandsen and Krishna (26). Samples of tissue extracts and standards for determination of cAMP were acetylated (25) and samples for determination of cGMP succinylated (26) as described in the original methods $(25,26)$. Acetylated or succinylated samples were incubated in $50 \mathrm{mM}$ sodium acetate buffer (pH 6.2) with anti-cAMP or anti-cGMP antibodies and [ $\left.{ }^{125} I\right]$ succinyl cAMP methyl ester or with [ $\left.{ }^{125} I\right]$ succinyl cGMP methyl ester for $16-24 \mathrm{~h}$ at $4^{\circ} \mathrm{C}$, and then the free and bound antigens were separated by ammonium-sulphate precipitation (24). Radioactivity of samples was counted in a gamma counter (Searle Analytical Gamma Counter, model 1285, Searle Diagnostics Inc., Des Plaines, Ill.). Specificity and sensitivity of antibodies were examined in preliminary experiments and found to be within the limits claimed by the manufacturer (Schwartz/ Mann Div., Becton, Dickinson \& Co., Orangeburg, N. Y.). Also, the increase in sensitivity by acetylation or by succinylation was in agreement with that reported by the authors (25, 26). With use of acetylation and succinylation of the standards and samples, the lower limit of sensitivity of RIA was 1 fmol for both cAMP and cGMP. In absence of added cold cAMP or cGMP, $\cong 50-60 \%$ of labeled antigen was bound to antibodies. Because RIA measurements were done on extracts in which cAMP and cGMP were not separated, the cross-reactivity of RIA for cAMP and cGMP was tested. Succinylated cAMP, even at 100 times higher concentration, did not interfere with measurements of succinylated cGMP in RIA for cGMP; and conversely, acetylated cGMP, even in the concentration 100 times higher than acetylated cAMP, did not interfere with the determination of acetylated cAMP by RIA for cAMP. The validity of cAMP and cGMP RIA measurements was also verified by the linearity of sample dilutions, by cAMP and cGMP hydrolysis with cyclic nucleotide phosphodiesterase, and by quantitative recovery of added unlabeled cyclic nucleotide to the extracts. Average coefficient of variation in RIA for cAMP and cGMP was $17 \%$.

Drug agonists and antagonists used in the present system were tested for interference with cAMP and cGMP determination by RIA. None of the tested agents at the concentrations higher than the highest concentrations used in the incubation mixtures interferes with determination of cAMP or cGMP by RIA, or with acetylation or succinylation procedures.

Radioactivity of tritiated tracer nucleotides was determined by liquid scintillation counting. The quantity of $\left[{ }^{3} \mathrm{H}\right] \mathrm{cAMP}$ and $\left[{ }^{3} \mathrm{H}\right] \mathrm{cGMP}$ tracers for recovery measurements which contributed to the final concentration of cyclic nucleotides were calculated and subtracted for each sample. After correction for recovery, and after subtraction of the added radioactive tracer, the contents of cAMP and cGMP in samples were expressed as $\mathrm{pmol} / \mathrm{mg}$ protein. In preliminary experiments we established that total protein in glomerular suspension was linearly proportional to the number of glomeruli in aliquots of samples in which glomeruli were counted in light microscope. The average protein content was $118 \pm 30 \mathrm{ng}$ protein/glomerulus $(n=7)$.

Because glomeruli, tubules, and slices were homogenized together with the incubation medium, the content of cAMP and cGMP represents the sum of the cyclic nucleotides contained within tissues and of that which leaked into the incubation medium. Accurate separation of glomeruli from medium would result in a prohibitive time delay between the 
end of the incubation and inactivation of the enzymes by homogenization in TCA. Likewise, the small sample size would make estimation of wet weight in the final incubation inaccurate. Cyclic nucleotide contents were expressed per protein presented, and measured in aliquots of the same TCA homogenate in which cyclic nucleotides were measured.

The protein contents were determined in aliquots of TCA homogenate after neutralization with $\mathrm{NaOH}$ by the method of Lowry et al. (27) as in our previous studies $(18,28,29)$. Alkaline phosphatase activity was measured with the method (30) employed in our earlier studies (31). Determinations of cyclic nucleotides by RIA, protein determination measurements of recovery, or alkaline phosphatase assay were run in duplicate or triplicate.

Glomeruli, tubules, or slices from the same pool of kidneys were incubated in the same day under exactly the same conditions with or without added hormones or drugs. Samples were also processed (extraction, RIA, and protein determination) at the same time, with the same batch of reagents. This design minimizes possible day-to-day variation between assays and preparative procedures, and allows paired comparisons. Glomeruli, tubules, or slices were incubated in duplicate aliquots for each condition (controls or with added drugs or antagonists); values of duplicates were averaged and entered as a single value $(n)$ for the purpose of statistical analysis. Exceptions are the results depicted in Fig. 1 (doseresponse curve for histamine) where each value is based on determinations in a single incubation tube.

The effects of drugs and hormones were evaluated both as a net difference from control and as relative $(\% \Delta)$ differences from control by $t$ test for paired comparisons. Other

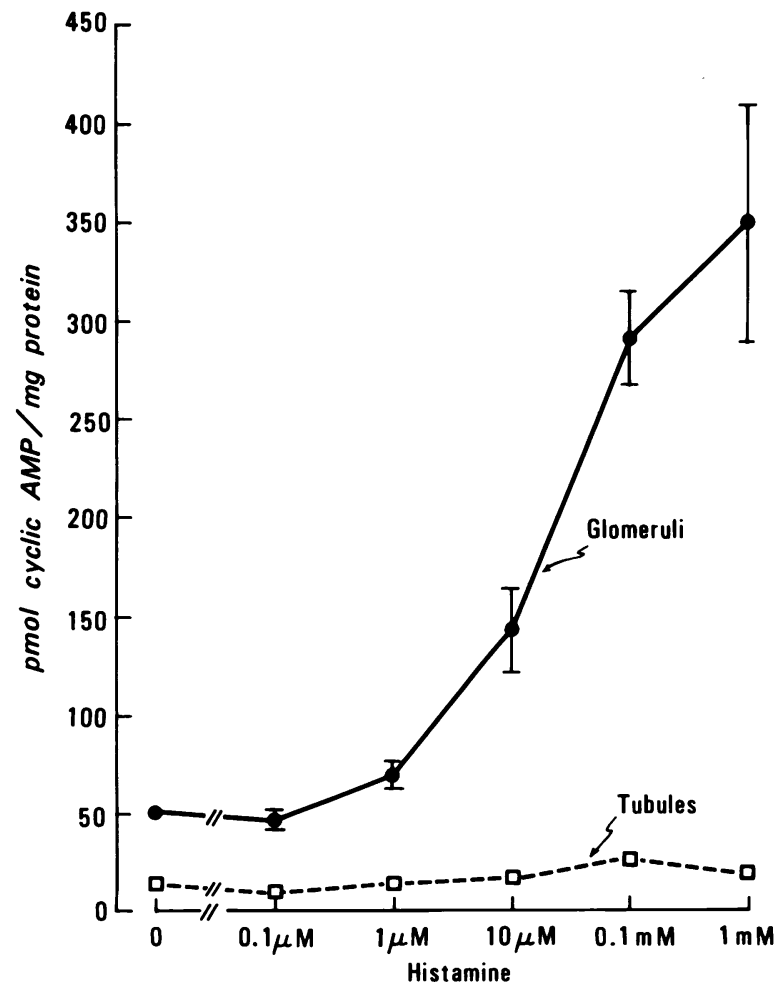

FIGURE 1 Effects of various doses of histamine on cAMP content in glomeruli $(\Theta)$ and in tubules $(\square)$. For incubation conditions see Methods. Each point represents mean \pm SEM of four measurements (see Methods). statistical evaluations were done with use of $t$ test for group comparisons, as appropriate. Values of $P>0.05$ were considered nonsignificant.

Materials. Synthetic 1,34-N-terminal tetratriacontapeptide of bovine PTH (activity 3,800 IU/mg) was purchased from Beckman Instruments, Inc., Spinco Division. Histamine, carbamylcholine, atropine, p-nitrophenylphosphate, and beef heart cyclic nucleotide phosphodiesterase were purchased from Sigma Chemical Co., St. Louis, Mo. Pyrilamine maleate was a product of $K$ and $K$ Laboratories, Inc., Plainview, N. Y.; Metiamide was a generous gift of Dr. Mendelson, Smith Kline \& French Laboratories, Philadelphia, Pa. Synthetic angiotensin-II (I-l-Valyl-octapeptide) was a product of CIBAGeigy Corp., Summit, N. J. Synthetic bradykinin was purchased from Calbiochem, San Diego, Calif. Ficoll was from Pharmacia Fine Chemicals, Piscataway, N. J., MIX from Aldrich Chemical Co., Inc., Milwaukee, Wis. Nylon mesh for filtration was purchased from Nytex Co., Niles, Ill. Other chemicals and biochemicals, all of highest purity grades, were purchased from standard suppliers.

$\left[{ }^{3} \mathrm{H}\right]$ Cyclic AMP and $\left[{ }^{3} \mathrm{H}\right]$ cyclic GMP for measurement of recoveries were purchased from New England Nuclear, Boston, Mass. Antibodies and ${ }^{125}$ I-labeled antigens were from RIA kits for determinations of cAMP and cGMP purchased from Schwartz/Mann Div., Becton, Dickinson \& Co.

\section{RESULTS}

Under the present incubation conditions, without addition of tested agents, the amounts of cAMP and cGMP accumulated in glomeruli were much higher than in tubules or tissue slices. Moreover, in tubules, the levels of cAMP were lower and the levels of cGMP higher than in slices. The cAMP:cGMP ratio in glomeruli was higher than in tubules (Table I).

The effects of the tested agents were evaluated both in terms of the net change from control levels as well as in relative terms as a percent change from the

\section{TABLE I}

Content of cAMP and cGMP in Isolated Glomeruli, Tubules, and Tissue Slices Incubated without Added Agents (Hormones, Inhibitors)

\begin{tabular}{lccr}
\hline & cAMP & cGMP & cAMP:cGMP* \\
\hline & \multicolumn{2}{c}{ pmol/mg protein } \\
& & \\
A Glomeruli (22) & $26.95 \pm 2.72 \S$ & $4.02 \pm 0.47$ & $10.8 \pm 2.7$ \\
B Tubules (22) & $6.90 \pm 0.79$ & $1.77 \pm 0.23$ & $5.4 \pm 1.1$ \\
C Slices (13) & $11.94 \pm 1.46$ & $0.95 \pm 0.07$ & $14.2 \pm 2.7$ \\
& & & \\
$P$ value for & & & \\
$\quad$ differences:" & & & \\
A $\leftrightarrow$ B: & $<0.001$ & $<0.001$ & $<0.01$ \\
B $\leftrightarrow$ C: & $<0.005$ & $<0.02$ & $<0.005$ \\
A $\leftrightarrow$ C: & $<0.001$ & $<0.001$ & NS \\
\hline
\end{tabular}

* cAMP:cGMP ratio was calculated from values measured in the same sample.

$\ddagger$ Number of experiments in parentheses (for details, see Methods).

$\$$ Mean \pm SEM.

" $t$ test. 
TABLE II

Effects of PTH on Cyclic Nucleotides in Glomeruli and Tubules

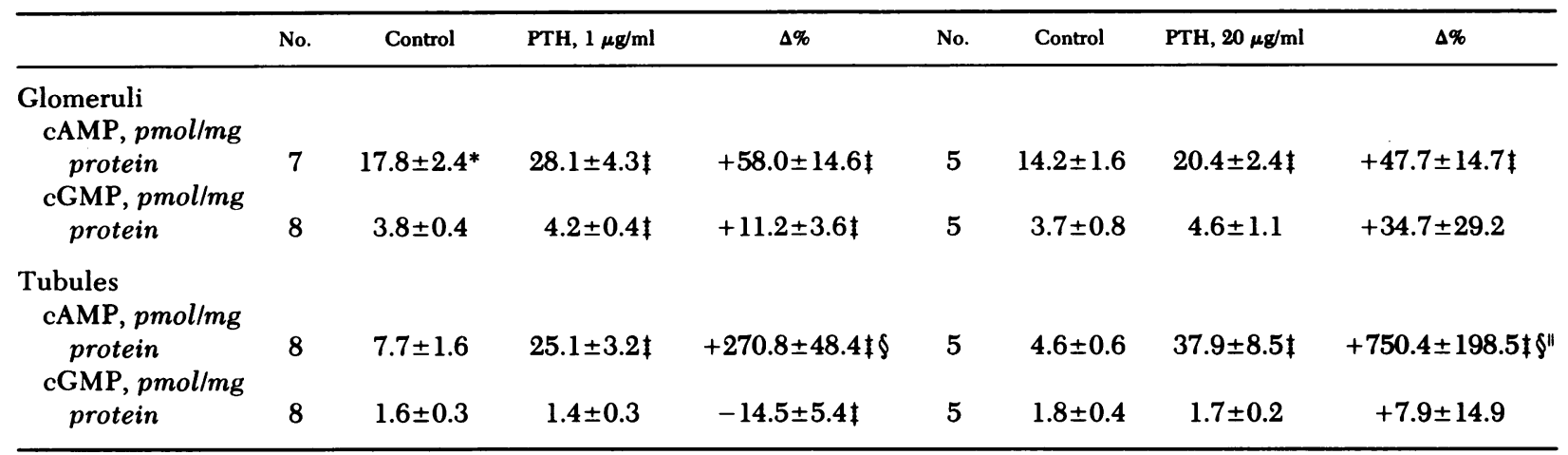

* Mean \pm SEM.

\# Significantly different from control and(or) $\Delta \%$ change is significant at $P<0.05$ or at higher level of significance (paired $t$ test).

$\S \Delta \%$ increase in cAMP significantly higher than with the same dose of PTH in glomeruli $(t$ test; $P<0.005)$.

" $\Delta \%$ increase in cAMP significantly higher than with lower dose of $(1 \mu \mathrm{g} / \mathrm{ml})$ of PTH $(t$ test; $P<0.005)$.

control values. Because our previous immunohistochemical study suggested that PTH may act on cAMP and cGMP in glomeruli as well as in tubules (17), the effect of this hormone was tested first. As shown in Table II, PTH always increased cAMP in glomeruli, and to a much higher extent in tubules. In cortical slices from the same kidney, the basal level as well as the response to the same dose $(1 \mu \mathrm{g} / \mathrm{ml})$ of PTH was similar $(+\Delta \% 388 \pm 108 ; n=5)$ to that in tubules. The extent of increases in cAMP in the response to $1 \mu \mathrm{g} / \mathrm{ml}$ PTH and to $20 \mu \mathrm{g} / \mathrm{ml}$ PTH was not significantly different in glomeruli, while in tubules the increase after $20 \mu \mathrm{g} / \mathrm{ml} \mathrm{PTH}$ was more extensive than the response to the lower dose (Table II). In glomeruli, PTH caused a slight cGMP elevation, while in tubules the cGMP was not changed in response to PTH or was slightly decreased (Table II). Changes in cGMP in response to PTH were much less extensive than those in cAMP.

In contrast to the moderate effects of PTH on cyclic nucleotides in glomeruli, histamine caused a striking increase of cAMP in glomeruli and a much smaller increase of cAMP in tubules (Table III); the relative $(\Delta \%)$ extent of cAMP increase in slices was similar to that in tubules (Table III). Histamine increases cAMP in glomeruli in a dose-dependent way (Fig. 1); the smaller cAMP increase in tubules also occurs within the same concentration-range of histamine (Fig. 1). Metiamide (a specific $\mathbf{H}_{2}$-receptor antagonist), or pyrilamine $\left(\mathrm{H}_{1}\right.$ receptor antagonist) alone, had no effect either on cAMP or cGMP levels (Fig. 2). Metiamide completely blocked the histamine-induced increase in cAMP levels in glomeruli; pyrilamine did not diminish significantly the cAMP response (Fig. 2). An analogous selective blocking action of metiamide on cAMP increases was observed in tubular preparations (data not shown). Histamine also increased cGMP in glomeruli, albeit to a much lesser degree than cAMP; the relative extent $(\Delta \%)$ of cGMP increase was similar in glomeruli, tubules, and tissue slices (Table III). In the present experiments, no consistent inhibitory effect of pyrilamine on

TABLE III

Effects of Histamine (0.1 mM) on Cyclic Nucleotides in Glomeruli, Tubules, and Tissue Slices

\begin{tabular}{|c|c|c|c|c|c|c|c|c|c|c|c|c|}
\hline & \multicolumn{4}{|c|}{ Glomeruli } & \multicolumn{4}{|c|}{ Tubules } & \multicolumn{4}{|c|}{ Cortical slices } \\
\hline & No. & Control & Histamine & $\Delta \%$ & No. & Control & Histamine & $\Delta \%$ & No. & Control & Histamine & $\Delta \%$ \\
\hline \multicolumn{13}{|l|}{$\begin{array}{l}\text { cAMP, } \\
\text { pmol/mg }\end{array}$} \\
\hline $\begin{array}{l}\text { protein } \\
\text { cGMP, } \\
\text { pmol/mg }\end{array}$ & 11 & $30.3 \pm 4.8^{*}$ & $211.8 \pm 28.9 \rrbracket$ & $+674.7 \pm 87.4 t$ & 9 & $5.3 \pm 0.6$ & $10.4 \pm 1.7 t$ & $+103.5 \pm 25.11 \S$ & 5 & $10.7 \pm 0.6$ & $24.7 \pm 2.2 \ddagger$ & $+130.7 \pm 13.8 t \S$ \\
\hline protein & 11 & $5.0 \pm 0.7$ & $8.0 \pm 1.3 \ddagger$ & $+66.3 \pm 17.01$ & 10 & $1.8 \pm 0.5$ & $2.9 \pm 0.81$ & $+56.1 \pm 17.61$ & 5 & $1.0 \pm 0.1$ & $1.9 \pm 0.3 \ddagger$ & $+88.0 \pm 24.0 \ddagger$ \\
\hline
\end{tabular}

* Mean \pm SEM.

† Significantly different from control and(or) $\Delta \%$ change is significant at $P<0.05$ or higher level of significance (paired $t$ test).

$\S \Delta \%$ increase significantly different from analogous value in glomeruli $(P<0.001 ; t$ test $)$. 

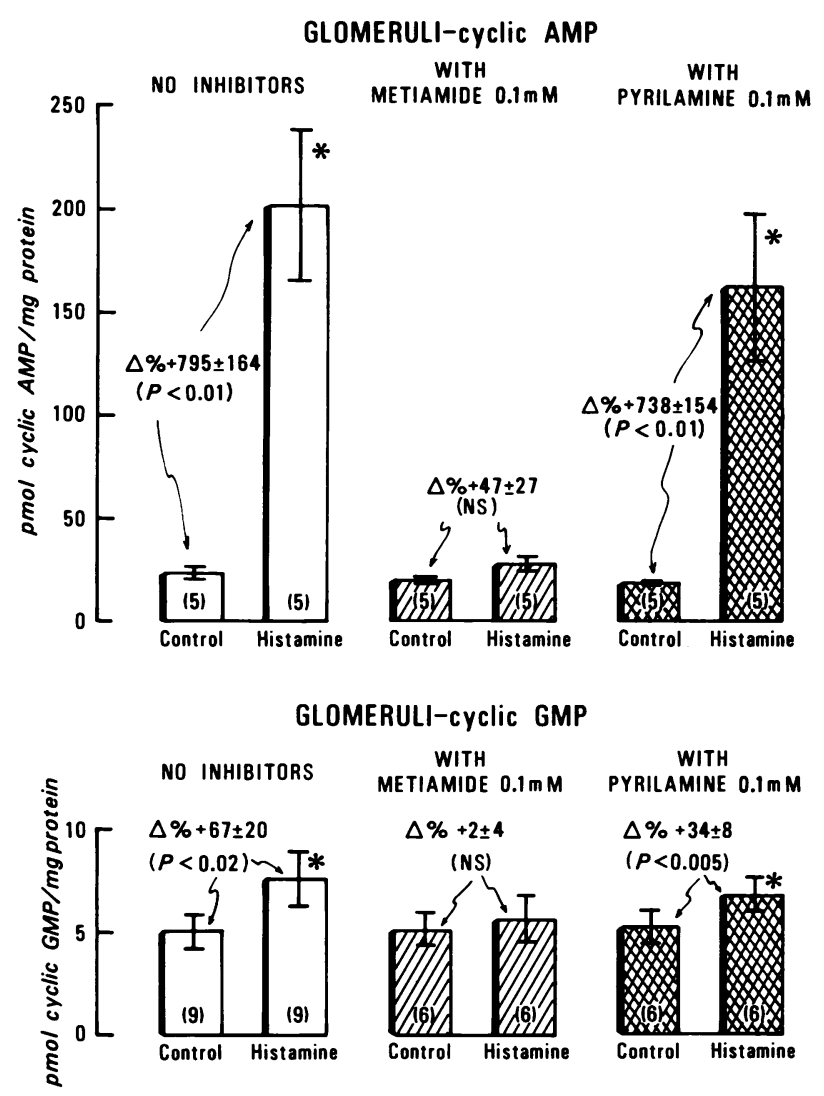

FIGURE 2 Effects of histamine antagonists metiamide and pyrilamine on increases in cAMP levels in glomeruli (upper panel) and increases in cGMP levels in glomeruli (lower panel). Each bar represents mean $\pm S E M$ and the number of experiments is indicated at the bottom of each column in parentheses (for details see Methods). Histamine concentration was always $0.1 \mathrm{mM}$. Asterisks (*) denote values significantly different from corresponding controls (without histamine) at $P<0.05$ or better (paired $t$ test). Statistical significance of relative $(\Delta \%)$ changes was evaluated in paired $t$ test. $\square$, Incubations in absence of inhibitors; $\square$, incubations in presence of $0.1 \mathrm{mM}$ metiamide; $\theta$, incubations in the presence of $0.1 \mathrm{mM}$ pyrilamine. Control values are not significantly different in the presence or absence of metiamide or pyrilamine, neither in glomeruli nor in tubules ( $t$ test).
cGMP was detected in glomeruli. On the other hand, metiamide prevented a significant increase of cGMP in the response to histamine (Fig. 2).

Carbamylcholine was found to be the most potent stimulator of cGMP of all the tested humoral agents in glomeruli (Table IV). Moreover, both absolute and relative $(\Delta \%)$ increase in cGMP was much higher in glomeruli than in tubules. In unfractionated cortical slices carbamylcholine caused an increase in cGMP $(+\Delta \% 164 \pm 43 \%, n=5)$ which was lower than in glomeruli and higher than in tubules. Carbamylcholine had a tendency to cause a slight increase also in cAMP, but these effects were minor in comparison with the effects on cGMP. Stimulation of cGMP was completely blocked by the addition of $10 \mu \mathrm{M}$ atropine; atropine itself had no effect of cGMP levels (Fig. 3). Similarly, atropine also prevented the stimulation of cGMP by carbamylcholine in tubules and slices (data not shown).

Angiotensin-II consistently lowered cAMP in glomeruli and, to a similar degree (in terms of $-\Delta \%$ ), in tubules (Table V). However, cGMP levels in the same preparations were not significantly changed after the addition of angiotensin-II. Bradykinin did not significantly change cGMP or cAMP in glomeruli or tubules. There was a tendency to increase cGMP and to decrease cAMP with bradykinin, but these changes were minor and not statistically significant (Table V).

\section{DISCUSSION}

In the interpretation of the present results it should be stressed that our experimental design was selected primarily to detect changes in cyclic nucleotides in response to humoral agents and, thus, in terms of absolute values, may not necessarily reflect the situation in vivo. The incubation time employed in our experiments $(2$ min) was relatively short, in an attempt to detect changes not only in cAMP but also in cGMP, which are known from other systems to be transient, with a rapid onset, an early peak of the response, and with subsequent fast decline in time (32-34). In control experiments,

TABLE IV

Effects of Carbamylcholine on Cyclic Nucleotides in Glomeruli and Tubules

\begin{tabular}{|c|c|c|c|c|c|c|c|c|}
\hline & \multicolumn{4}{|c|}{ Glomeruli } & \multicolumn{4}{|c|}{ Tubules } \\
\hline & No. & Control & $\begin{array}{c}\text { Carbamylcholine, } \\
0.5 \mathrm{mM}\end{array}$ & $\Delta \%$ & No. & Control & $\begin{array}{c}\text { Carbamylcholine, } \\
0.5 \mathrm{mM}\end{array}$ & $\Delta \%$ \\
\hline $\begin{array}{l}\text { cAMP, pmol/mg } \\
\text { protein } \\
\text { cGMP, pmol/mg }\end{array}$ & 10 & $31.0 \pm 4.7^{*}$ & $38.6 \pm 6.5 \ddagger$ & $+28.2 \pm 9.2 \ddagger$ & 10 & $7.1 \pm 1.1$ & $7.6 \pm 0.9$ & $+9.8 \pm 11.6$ \\
\hline protein & 10 & $2.9 \pm 0.5$ & $9.0 \pm 1.3 \ddagger$ & $+294.8 \pm 76.8 \ddagger \S$ & 10 & $1.6 \pm 0.3$ & $2.5 \pm 0.5 \ddagger$ & $+70.6 \pm 20.3 \ddagger$ \\
\hline
\end{tabular}

* Mean \pm SEM.

\$ Significantly different from control and(or) $\Delta \%$ is significant at $P<0.05$ or higher level of significance (paired $t$ test).

$\S \Delta \%$ increase significantly higher than in tubules $(t$ test). 


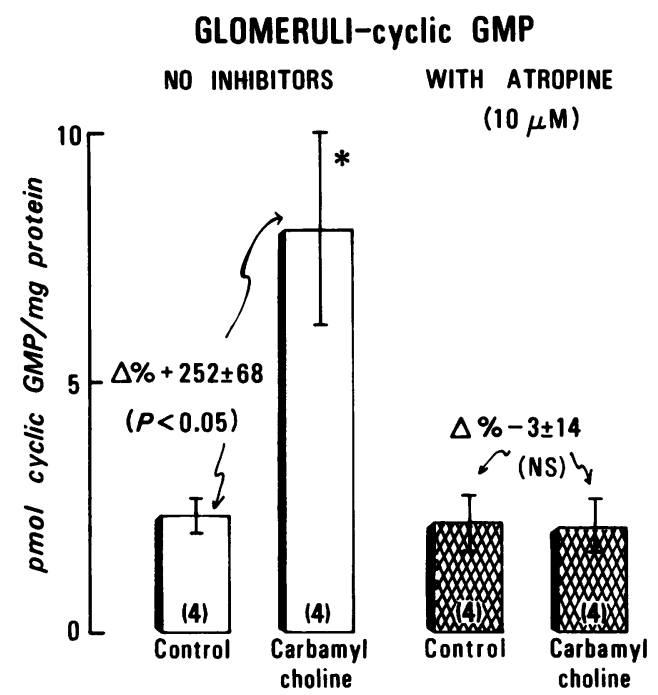

FIGURE 3 Effects of carbamylcholine and atropine on cGMP in glomeruli. Each bar represents mean \pm SEM and the number of experiments is indicated at the bottom of columns in parentheses. Carbamylcholine was added to the concentration of $0.5 \mathrm{mM}$ and atropine $10 \mu \mathrm{M}$. Asterisk (*) denotes value significantly different from control (without carbamylcholine) (paired $t$ test; $P<0.05$ ). Levels with atropine alone were not significantly different from control without added agents $(t$ test). Statistical significance of relative $(\Delta \%)$ changes was evaluated by paired $t$ test. $\square$, Incubations in the absence of atropine; $\square$, incubations in the presence of $10 \mu \mathrm{M}$ atropine.

we explored responses of cyclic nucleotides to agents also at longer incubation periods. Responses at $5 \mathrm{~min}$ did not differ from the 2 -min period, and at $15 \mathrm{~min}$ tended to decline. Inclusion of MIX, which inhibits both cAMP and cGMP phosphodiesterase $(16,35)$, was aimed to optimize conditions for detecting increases in cyclic nucleotides, elicited by the tested agents. Without inclusion of MIX, control levels of cAMP and cGMP were lower and the response to hormonal agents less pronounced. But, the selected concentration $(0.5 \mathrm{mM})$ of MIX would not inhibit cyclic nucleotide breakdown completely (36), thus allowing us to also detect decreases in cyclic nucleotides induced by the tested agents.

Interpretation of the present results is focused primarily on findings in glomeruli which represent a homogeneous preparation. Observations on tubular suspensions, which are necessarily a mixture of various tubular segments of the nephron existing in renal cortex, or observations on unfractionated tissue slices are much less specific and were used here primarily for comparison and validation of observations on glomeruli obtained from the same kidneys. Increased sensitivity of RIA for cAMP by acetylation (25) of samples, and for cGMP by succinylation of samples (26), allowed measurements in small quantity of tissue; high specificity of anti-cAMP and anti-cGMP antibodies allowed simultaneous measurements of both cyclic nucleotides in the same tissue extract excluding cross-reactivity of cyclic nucleotides.

Under control conditions, cAMP and cGMP levels were much higher in glomeruli than in tubules; cAMP levels in tubules were, in turn, lower than in unfractionated tissue slices (Table I). This observation suggested that while glomeruli contributed only $8 \%$ of the volume to the total mass of renal cortical tissue (37), cyclic nucleotides from glomeruli may contribute substantially to the total renal cortical content of cAMP and cGMP, if the cyclic nucleotides are measured in the unfractionated kidney tissue. It should be realized that structures other than glomeruli and tubules (such as vascular elements) could also contribute to the cyclic nucleotide level in unfractionated slices; the ratio of cAMP to cGMP measured in vitro might differ from that in vivo.

In basic agreement with previous studies on glomerular adenylate cyclase (10-12), PTH increased cAMP in glomeruli as well as in tubules, but to a lesser degree. The increase of cAMP after PTH is of a lesser extent than might have been expected from considerable stimulation of adenylate cyclase activity by PTH

TABLE V

Effects of Angiotensin-II (2 $\mu M)$ and Bradykinin (20 $\mu M)$ on Cyclic Nucleotides in Glomeruli and in Tubules

\begin{tabular}{|c|c|c|c|c|c|c|c|c|}
\hline & No. & Control & Angiotensin-II & $\Delta \%$ & No. & Control & Bradykinin & $\Delta \%$ \\
\hline \multicolumn{9}{|l|}{ Glomeruli } \\
\hline cAMP, pmol/mg protein & 8 & $28.8 \pm 4.2^{*}$ & $14.8 \pm 2.0 \ddagger$ & $-45.5 \pm 8.2 \ddagger$ & 5 & $30.5 \pm 7.5$ & $29.8 \pm 9.5$ & $-4.6 \pm 8.9$ \\
\hline cGMP, pmol/mg protein & 8 & $5.3 \pm 0.9$ & $4.9 \pm 0.9$ & $-11.7 \pm 9.2$ & 5 & $5.1 \pm 1.0$ & $5.7 \pm 1.3$ & $+9.4 \pm 5.1$ \\
\hline \multicolumn{9}{|l|}{ Tubules } \\
\hline cAMP, pmol/mg protein & 7 & $5.3 \pm 0.8$ & $3.7 \pm 0.6$ & $-33.0 \pm 7.3 \ddagger$ & 4 & $5.8 \pm 0.3$ & $5.6 \pm 0.6$ & $-21.1 \pm 11.2$ \\
\hline cGMP, pmol/mg protein & 7 & $2.0 \pm 0.6$ & $2.0 \pm 0.5$ & $+1.4 \pm 12.7$ & 4 & $1.2 \pm 0.2$ & $1.6 \pm 0.2$ & $+33.8 \pm 17.1$ \\
\hline
\end{tabular}

* Mean \pm SEM.

† Significantly different from control and(or) $\Delta \%$ change is significant at $P<0.05$ or higher level of significance (paired $t$ test). 
in rabbit and rat glomeruli preparations $(10,11)$ reported from other laboratories. Such discrepancy may be a result of differences in species, incubation time, rate of cAMP catabolism, or other factors. The possibility that the rather small PTH effect on glomerular cAMP is a result of contamination of glomeruli with PTH-responsive tubules cannot be absolutely ruled out but is highly unlikely for several reasons. First, the increases of cAMP in glomeruli in experiments on rat kidney perfused with PTH were detected by immunohistochemical method, where cross-contamination with tubular cAMP is completely avoided (17). Imbert et al. (12) found PTH-stimulated adenylate cyclase in rabbit glomeruli in experiments in which glomeruli were separated from tubules by micromanipulation techniques. It should be noted that in the present experiments, unlike in tubules, the cAMP response in glomeruli cannot be further increased with a higher dose of PTH (Table II), indicating a different behavior of the PTHsensitive cAMP system in glomeruli and tubules.

Lower glomerular cAMP response to PTH than in tubules does not appear to be a result of damage of the cAMP system which could occur in the course of preparation of glomeruli because under identical conditions, histamine caused a striking increase in glomerular cAMP, much higher than in tubules (Table III); and this happened even when the effects of PTH and histamine were tested simultaneously in the same preparation of glomeruli and tubules.

Changes in cGMP in response to PTH were minor both in glomeruli and tubules, compared with the changes in cAMP. The slight increase in cGMP in glomeruli appears to be in basic agreement with our previous findings of increased immunoreactive cGMP primarily in glomeruli in the PTH-perfused kidney (17). It should be stressed, however, that changes in cGMP levels found in present experiments are minor, and the interpretation should be extremely guarded. Nevertheless, the changes in cGMP levels observed in experiments with PTH or with other agents could not be explained by analytical error, because no crossreactivity with cAMP and cGMP in RIA in range of cyclic nucleotide levels found in our experiments was detected.

Profound stimulation of cAMP in glomeruli by histamine (Table III, Fig. 1) is the most striking response of the glomerular cyclic nucleotide system to a humoral agent detected in this study. Blockade of this response by metiamide but not by pyrilamine indicates that histamine increases cAMP through its action on $\mathrm{H}_{2}$-receptors. Because the cAMP response to histamine was much lower in tubules, or in tissue slices, it indicates that the $\mathrm{H}_{2}$-receptor-sensitive cAMP system is rather a specific component of glomeruli. Only future studies could discriminate whether the small cAMP response to his- tamine in tubules is intrinsic to tubules or whether it is a result of some other component included in our tubular suspension.

Histamine also increased moderately but consistently cGMP in glomeruli, in tubules, and in slices (Table III); the latter observation is consistent with a preliminary report by DeRubertis and Craven (38). Results with histamine blocking agents indicate that, as in the case of cAMP, metiamide, rather than pyrilamine, diminishes increases of cGMP in glomeruli. Such a finding differs from observations on smooth muscle preparations from umbilical arteries (33) or from trachea (23), where histamine-elicited cGMP increases were inhibited by $\mathrm{H}_{1}$-antagonists, but not by $\mathrm{H}_{2}$-blocking agents (33). Thus, the present finding may be either an intrinsic feature of glomeruli or, alternatively, cGMP increases in glomeruli could be secondary to the huge increase in cAMP elicited by histamine. Mechanisms invoked for interpretation of such a phenomenon may include stimulation of guanylate cyclase by cAMP, such as reported for liver nuclei (39), or inhibition of cGMP phosphodiesterase activity in glomeruli by cAMP, as observed in our own recent experiments (16).

The stimulatory effect of the cholinergic agent carbamylcholine on cGMP was reported previously for many tissues (40), including kidney cortex (32). Our present results point out that a cholinergic agent-responsive cGMP system is especially active in glomeruli. In addition to increases in cGMP, carbamylcholine also caused a slight increase in cAMP in glomeruli; the mechanism of such effect, which was also observed in other laboratories $(23,34,41)$, is not clear. The blocking effect of atropine (Fig. 3) indicates that cholinergic agents act on muscarinic receptor in glomeruli to stimulate the cGMP formation.

It is of major interest that high histamine content in glomeruli was detected by histochemical method (42), and that active histamine synthetase was recently described in isolated rat kidney glomeruli (43).

Perhaps the most relevant implication of the present findings is the fact that histamine and cholinergic agents, through mediation of cyclic nucleotide system, play a major role in pathogenesis of inflammation, especially in response to immune injury as shown in several extrarenal systems $(8-10,44)$. Our present finding that cAMP system and cGMP system in glomeruli are highly responsive to histamine and cholinergic agents suggests that these mediators could play an important role in pathogenesis of various glomerulopathies, namely inflammatory changes caused by immune injury $(8-10$, $44,45)$.

The effect of angiotensin-II to lower cAMP but not cGMP is not limited to glomeruli, but occurs to a slightly lesser extent in tubules too. In other systems, angiotensin-II was reported to decrease cAMP levels, but 
only when elevated by cAMP agonists $(46,47)$. Angiotensin-II was also reported to bind $(48,49)$ on isolated glomeruli and to cause glomerular contraction (48); the latter effect was also observed in our laboratory. ${ }^{2}$ Relation of the effects of angiotensin-II on cAMP to the above mentioned phenomena $(48,49)$, or to its effects on single nephron dynamics in vivo $(1,3,4)$, remains to be established.

Absence of bradykinin effects in the isolated glomeruli and tubules in contrast to marked responses to other agents (carbamylcholine, histamine) may indicate that this peptide does not act on glomeruli or tubules directly. Known effects of bradykinin on renal function or single nephron dynamics $(1,5)$ could entirely be a result of the action on extraglomerular vasculature.

Finally, it was observed recently that high levels of PTH could alter the function of at least certain subpopulation (cortical superficial) of glomeruli $(2,50)$; such glomerular effects could conceivably be mediated via cyclic nucleotides.

Thus, in summary, our results demonstrate the presence of a highly active cyclic nucleotide system in glomeruli which differs markedly from tubular elements of renal cortex. Remarkable sensitivity of the cAMP system to $\mathrm{H}_{2}$-histamine stimulation and the cGMP system to cholinergic stimuli suggests that these agents could, through mediation of cyclic nucleotides, play an important role in the pathogenesis of inflammatory glomerular tissue injury. Exact link between the effects of PTH and angiotensin-II on glomerular cyclic nucleotides, and functional effects of these agents on glomeruli in vivo, will require both more precise localization of biochemical changes in various areas and cell types in glomeruli, as well as careful analysis of single nephron function in vitro and in vivo.

\section{ACKNOWLEDGMENTS}

Mrs. Denise M. Heublein and Mrs. Yvonne S. F. Hui provided expert technical assistance, and Mrs. Ardith M. Walker provided expert secretarial assistance.

This research was supported by U. S. Public Health Service Research grants AM-16105 and AM-21114 from the National Institute of Arthritis, Metabolism, and Digestive Diseases and by the Mayo Foundation.

\section{REFERENCES}

1. Brenner, B. M., C. Baylis, and W. M. Deen. 1976. Transport of molecules across renal glomerular capillaries. Physiol. Rev. 56: 502-534.

2. Ichikawa, I., H. D. Humes, T. P. Dousa, and B. M. Brenner. 1978. Influence of parathyroid hormone on glomerular ultrafiltration in the rat. Am. J. Physiol. 234: F393-F401.

3. Blantz, R. C., K. S. Konnen, and B. J. Tucker. 1976. Angiotensin II effects upon the glomerular microcirculation and ultrafiltration coefficient of the rat. J. Clin. Invest. 56: 419-434.

${ }^{2}$ Torres, Scott, and Dousa. Unpublished observations.
4. Bohrer, M. P., W. M. Deen, C. R. Robertson, and B. M. Brenner. 1977. Mechanism of angiotensin II-induced proteinuria in the rat. Am. J. Physiol. 233: F13-F21.

5. Baylis, C., W. M. Deen, B. D. Myers, and B. M. Brenner. 1976. Effects of some vasodilator drugs on transcapillary fluid exchange in renal cortex. Am. J. Physiol. 230: 1148-1158.

6. Knox, F. G., and C. E. Ott. 1976. Filtration pressure equilibrium in the dog glomerulus. Proc. Int. Congr. Nephrol. 216-222.

7. Austen, K. F. 1971. Immunological Diseases. M. Samter, editor. Little, Brown and Co., Boston. 2nd edition. 332.

8. Kaliner, M., and K. F. Austen. 1975. Immunologic release of chemical mediators from human tissues. Annu. Rev. Pharmacol. 15: 177-189.

9. Parker, C. W., T. J. Sullivan, and H. J. Wedner. 1974. Cyclic AMP and the immune response. Adv. Cyclic Nucleotide Res. 4: 1-79.

10. Lichtenstein, L. M. 1976. Hormone receptor modulation of cAMP in the control of allergic and inflammatory responses. In The Role of Immunological Factors in Infections, Allergic and Antiimmune Processes. R. F. Beers, Jr., and E. G. Bassett, editors. Raven Press, New York. 339-354.

11. Sraer, J., R. Ardaillou, N. Loreau, and J. C. Sraer. 1974. Evidence for parathyroid hormone sensitive adenylate cyclase in rat glomeruli. Mol. Cell. Endocr. 1: 285-294.

12. Imbert, M., D. Chabardes, and F. Morel. 1974. Hormone sensitive adenylate cyclase in isolated rabbit glomeruli. Mol. Cell. Endocr. 1: 295-304.

13. Schlondorff, D., P. Yoo, and B. E. Alfert. 1977. Hormonal effects on cyclic AMP in isolated rat glomeruli. Kidney Int. 12: 573. (Abstr.)

14. Helwig, J. J., C. Bollack, P. Mandel, and C. Goridis. 1975. Renal cortex guanylate cyclase preferential enrichment in glomerular membranes. Biochim. Biophys. Acta. 377: 463-472.

15. Torres, V. E., Y. S. F. Hui, S. V. Shah, and T. P. Dousa. 1977. Cyclic $3^{\prime}, 5^{\prime}$-nucleotide phosphodiesterase in isolated glomeruli. Kidney Int. 12: 545. (Abstr.)

16. Torres, V. E., Y. S. F. Hui, S. V. Shah, T. E. Northrup, and T. P. Dousa. 1978. Cyclic nucleotide phosphodiesterases in glomeruli of rat renal cortex. Kidney Int. 14: 444-451.

17. Dousa, T. P., L. D. Barnes, S-H. Ong, and A. L. Steiner. 1977. Immunohistochemical localization of $3^{\prime}, 5^{\prime}$-cyclic AMP and 3',5'-cyclic GMP in rat renal cortex: Effect of parathyroid hormone. Proc. Natl. Acad. Sci. U. S. A. 74: 3569-3573.

18. Knox, F. G., J. Preiss, J. K. Kim, and T. P. Dousa. 1977. Mechanism of resistance to the phosphaturic effect of the pharathyroid hormone in the hamster. J. Clin. Invest. 59: $675-683$.

19. Nørgaard, J. O. R. 1976. A new method for the isolation of ultrastructurally preserved glomeruli. Kidney Int. 9: 278-285.

20. Taylor, D. G., R. G. Price, and D. Robinson. 1971. The distribution of some hydrolases in glomeruli and tubular fragments prepared from rat kidney by zonal centrifugation. Biochem. J. 122: 641-645.

21. Murad, F., V. Manganiello, and M. Vaughan. 1971. A simple sensitive protein binding assay for guanosine 3',5'-monophosphate. Proc. Natl. Acad. Sci. U. S. A. 68: 736-739.

22. Kapoor, C. L., and G. Krishna. 1977. Hormone-induced cyclic guanosine monophosphate secretion from guinea pig pancreatic lobules. Science (Wash. D. C.). 196: 10031005. 
23. Katsuki, S., and F. Murad. 1976. Regulation of adenosine cyclic $3^{\prime}, 5^{\prime}$-monophosphate levels and contractility in bovine tracheal smooth muscle. Mol. Pharmacol. 13: 330341.

24. Steiner, A. L., C. W. Parker, and D. M. Kipnis. 1972. Radioimmunoassay for cyclic nucleotides. I. Preparation of antibodies and iodinated cyclic nucleotides. J. Biol. Chem. 247: 1106-1113.

25. Harper, J. F., and G. Brooker. 1975. Femtomole sensitive radioimmunoassay for cyclic AMP and cyclic GMP after $2^{\prime} 0$ acetylation by acetic anhydride in aqueous solution. J. Cyclic Nucleotide Res. 1: 207-218.

26. Frandsen, E. K., and G. Krishna. 1976. A simple ultrasensitive method for the assay of cyclic AMP and cyclic GMP in tissues. Life Sci. 18: 529-542.

27. Lowry, O. H., N. J. Rosenbrough, A. L. Farr, and R. J. Randall. 1951. Protein measurement with the Folin phenol reagent. J. Biol. Chem. 193: 265-275.

28. Kim, J. K., P. P. Frohnert, Y. S. F. Hui, L. D. Barnes, G. M. Farrow, and T. P. Dousa. 1977. Enzymes of cyclic $3^{\prime}, 5^{\prime}$-nucleotide metabolism in human renal cortex and renal adenocarcinoma. Kidney Int. 12: 172-183.

29. Dousa, T. P., and L. D. Barnes. 1977. Regulation of protein kinase by vasopressin in renal medulla in situ. Am. J. Physiol. 232: F43-F49.

30. Lansing, A. I., M. L. Belkhode, W. E. Lynch, and J. Lieberman. 1967. Enzymes of plasma membrane liver. J. Biol. Chem. 242: 1772-1775.

31. Dousa, T. P., C. G. Duarte, and F. G. Knox. 1976. Effect of colchicine on urinary phosphate and regulation by parathyroid hormone. Am. J. Physiol. 231: 61-65.

32. DeRubertis, F. R., and P. A. Craven. 1976. Properties of the guanylate cyclase-guanosine $3^{\prime}, 5^{\prime}$-monophosphate system of rat renal cortex. J. Biol. Chem. 251: 4651-4658.

33. Clyman, R. I., J. A. Sandler, V. C. Manganiello, and M. Vaughan. 1975. Guanosine 3',5'-monophosphate and adenosine $3^{\prime}, 5^{\prime}$-monophosphate content of human umbilical artery. Possible role in perinatal arterial patency and closure. J. Clin. Invest. 55: 1020-1025.

34. Stoner, J., V. C. Manganiello, and M. Vaughan. 1974. Guanosine cyclic $3^{\prime}, 5^{\prime}$-monophosphate and guanylate cyclase activity in guinea pig lung: Effects of acetylcholine and cholinesterase inhibitors. Mol. Pharmacol. 10: 144161.

35. Zenser, T. V., P. A. Craven, F. R. DeRubertis, and B. B. Davis. 1977. Differential inhibition of cyclic AMP and cyclic GMP hydrolysis in rat renal cortex. Arch. Biochem. Biophys. 178: 598-606.

36. Hall, D. A., L. D. Barnes, and T. P. Dousa. 1977. Cyclic AMP in action of antidiuretic hormone: Effects of exogenous cyclic AMP and its new analog. Am. J. Physiol. 232: F368-F376.
37. Burg, M. B., and J. Orloff. 1966. Effect of temperature and medium $\mathrm{K}$ on $\mathrm{Na}$ and $\mathrm{K}$ fluxes in separated renal tubules. Am. J. Physiol. 211: 1005-1010.

38. DeRubertis, F. R., and P. A. Craven. 1976. Modulation of renal cortical cyclic GMP by calcium and sodium dependent and independent mechanisms. Clin. Res. 24: 398A. (Abstr.)

39. Earp, H. S., P. Smith, S-H. Ong, and A. L. Steiner. 1977. Regulation of hepatic nuclear guanylate cyclase. Proc. Natl. Acad. Sci. U. S. A. 74: 946-950.

40. Goldberg, N. D., and M. K. Haddox. 1977. Cyclic GMP metabolism and involvement in biological regulation. Annu. Rev. Biochem. 46: 823-896.

41. Murad, F., and H. Kimura. 1974. Cyclic nucleotide levels in incubations of guinea pig trachea. Biochim. Biophys. Acta. 343: 275-286.

42. Juhlin, L. 1967. Determination of histamine in small biopsies and histological sections. Acta Physiol. Scand. 71: $30-36$.

43. Heald, J. I., and T. M. Hollis. 1976. Histadine decarboxylase-mediated histamine synthesis in glomeruli from rat kidneys. Am. J. Physiol. 230: 1349-1353.

44. Ignarro, L. J. 1975. Hormonal control of lysosomal enzyme release from human neutrophils by cyclic nucleotides and autonomic neurohormones. In Cyclic Nucleotides in Diseases. B. Weiss, editor. University Park Press, Baltimore, Md. 187-210.

45. Bourne, H. R., L. M. Lichtenstein, K. L. Melmon, C. S. Henney, Y. Weinstein, and G. M. Shearer. 1974. Modulation of inflammation and immunity by cyclic AMP. Receptors for vasoactive hormones and mediators of inflammation regulate many leukocyte functions. Science (Wash. D. C.). 184: 19-28.

46. Harbon, S., and H. Clauser. 1971. Cyclic adenosine $3^{\prime}, 5^{\prime}$ monophosphate levels in rat myometrium under influence of epinephrine, prostaglandin and oxytocin. Correlations with uterus motility. Biochem. Biophys. Res. Commun. 44: 1496-1503.

47. Webster, S. K., and N. Beck. 1977. Interaction of prostaglandin $\mathrm{E}_{2}$ and angiotensin II on cyclic AMP in kidney and the aorta. Fed. Proc. 36: 402. (Abstr.)

48. Sraer, J. D., J. Sraer, R. Ardaillou and O. Mimoune. 1974. Evidence for renal glomerular receptors for angiotensin II. Kidney Int. 6: 241-246.

49. Osborne, M. J., B. Droz, P. Meyer, and F. Morel. 1975. Angiotensin-II: Renal localization in glomerular mesangial cells by autoradiography. Kidney Int. 8: 245-254.

50. Humes, H. D., I. Ichikawa, J. L. Troy, and B. M. Brenner. 1978. Evidence for a parathyroid hormone-dependent influence of calcium on the glomerular ultrafiltration coefficient. J. Clin. Invest. 61: 32-40. 